\title{
Hospitalizations and re-Hospitalizations Due to Tuberculosis: Economic Costs and Spatial Distribution Analysis in an Endemic Northeastern City, Brazil
}

Maria Concebida da Cunha Garcia', Ana Angélica Rêgo de Queiroz , Marcela Paschoal Popolin ${ }^{1}$, Mellina Yamamura1, Marcelino Santos Netoㄹ, Luiz Henrique Arroyo ${ }^{1}$, Antônio Carlos Vieira Ramos ${ }^{1}$, Luana Seles Alves ${ }^{1}$, Francisco Chiaravalloti Neto ${ }^{3}$, Carla Nunes ${ }^{4}$, Bertha Cruz Enders ${ }^{5}$, Ione Carvalho Pinto ${ }^{1}$, Severina Alice da Costa Uchôa ${ }^{6}$, Ricardo Alexandre Arcêncio ${ }^{1}$

\section{Abstract}

Introduction: In Brazil, preventable hospitalizations and re-hospitalizations due to tuberculosis represent increased costs for the health system. The aim was to analyze the sociodemographic and clinical profile of individuals who needed preventable hospitalizations and re-hospitalizations due to tuberculosis, the costs to the local health system, and the spatial pattern for the occurrence of these events in a Brazilian endemic city.

Methods: Descriptive and exploratory study conducted in Natal, city located in the Northeast region of Brazil. The population comprised all cases of preventable hospitalizations and re-hospitalizations due to tuberculosis occurring between 2008 and 2013 obtained from the Hospital Information System. The neighborhoods and census tracts were chosen as the geographical units. Descriptive statistics and nonparametric tests were applied. Position and dispersion measures were used to analyze the costs. The gross rates were estimated, softened by the Global Empirical Bayesian Method. The Global and Local Moran indices were used to evaluate the spatial dependency.

Results: 569 cases of hospitalizations due to tuberculosis were identified: $97.4 \%$ were pulmonary form; $62.0 \%$ between 30 and 59 years old; $77.7 \%$ male; $87.3 \%$ mulatto. In the total group of hospitalizations, $13.4 \%$ died and $17.9 \%$ were readmitted. In total, US\$ 470,370.07 was spent on preventable hospitalizations and re-hospitalizations due to tuberculosis, with an annual mean cost of US\$78,395.01, median
1 Maternal-Infant and Public Health Nursing Department, University of São Paulo at Ribeirão Preto College of Nursing, Ribeirão Preto, SP, Brazil.

2 Center of Social Sciences, Health and Technology, Federal University of Maranhão,Imperatriz, MA, Brazil.

3 Department of Epidemiology, School of Public Health, University of São Paulo, São Paulo, SP, Brazil.

4 Centro de Investigação em Saúde Pública. Escola Nacional de Saúde Pública, Universidade Nova de Lisboa, Lisboa, Portugal.

5 Nursing Department, Center of Health Sciences, Federal University of Rio Grande do Norte, Campus Universitário, BR 101, Natal, RN, Brazil.

6 Department of Group Health, Federal University of Rio Grande do Norte, Natal, Rio Grande do Norte, Brazil.

Contact information:

Maria Concebida da Cunha Garcia.

Address: Avenida Bandeirantes, 3900, Ribeirão Preto, SP, Brazil, CEP 14049-900.

Tel/Fax: (+55) (84) 99332330.

झ concycg@yahoo.com.br 
amounts of US\$392.70 per hospitalization and US\$1,342.19 per rehospitalization. The spatial distribution of the events was not random, with high rates identified in neighborhoods of the East and West Health Districts.

Conclusions: The non-randomness in the spatial pattern of preventable hospitalizations and re-hospitalizations cases due to tuberculosis suggests frailty in the access to Primary Health Care and appoints vulnerable spatial areas to these events. The recognition of these areas can contribute to public management in the improvement of health service access and to the equitable and efficient use of health resources, aiming to reduce the hospitalization costs.

\section{Keywords}

Tuberculosis; Hospitalizations; Re-hospitalizations; Health Information Systems; Health Costing; Spatial Analysis.

\section{Introduction}

The challenging measures that the World Health Organization (WHO) has set for the health systems around the world include the control and elimination of tuberculosis (TB) by 2050 [1]. In 2013, nine million new cases were observed globally, three million of which were unable to get access to health services. This situation reflects the challenge of establishing care systems that are able to reach all segments of the population affected by TB [2].

In Brazil, despite the free availability of TB diagnosis and treatment technologies in Primary Health Care (PHC), frailties continue to exist in the health system with regards to its response to the population's main demands and needs, in view of social, demographic and epidemiological changes $[3,4]$. The country ranks $22^{\text {nd }}$ in case numbers on the list of 22 countries that concentrate about $80 \%$ of the global TB burden, with an incidence rate of 33.5 cases per 100,000 inhabitants and a mortality rate of 2.3 per 100,000 inhabitants $[2,5]$.

Natal is considered a priority city for the control of the disease in Brazil, with an incidence rate of 42.9 cases/100,000 inhabitants and a mortality rate of 2.1 deaths/100,000 inhabitants in 2014 [5]. In 2013, $54.4 \%$ of the new cases of active pulmonary TB evolved to cure and 9.3\% dropped out of the treatment [5]. These rates are lower than the national average and the targets agreed upon by the Brazilian Ministry of Health $(\mathrm{BMH})$ and the $\mathrm{WHO}$, which recommend the cure of at least $85.0 \%$ of cases of active pulmonary tuberculosis.

In the same epidemiological context, preventable hospitalizations and re-hospitalizations due to TB have an expressive impact, in view of their high costs which the local health systems cannot always bear. TB ranks ninth among the infectious causes of hospitalization and seventh in hospital expenses due to infectious diseases in the Unified Health System (SUS) [6]. It was estimated that, in 2013, hospitalizations costs due to TB in Brazil amounted to approximately $R \$ 28$ million [7]. Ninety-five percent of this amount was spent on hospitalizations that are classified as preventable, which could have been reduced and/or avoided through early diagnosis, timely treatment and problem-solving management at the PHC level $[8,9]$.

In that sense, reducing the preventable hospitalizations and re-hospitalizations due to TB can contribute to control health costs in the country and around the world $[10,11]$, as hospitalization 
experiences are dominant and exceed outpatient treatment by up to one hundred times [12].

Nevertheless, it should be highlighted that these events are not only related to access, structure and quality aspects of PHC and available care services. They can also be associated with the patient's characteristics, the individual or community's behaviors in search of care and with the environmental and social factors of the context s/he is inserted in $[10,13]$. In addition, the health resources are not always allocated efficient, universal and equitably among the populations and regions, determining variations in the access and use of health services $[14,15]$, which has entailed different risks of illness and distinct forms of coping and morbidity.

Thus, in view of the magnitude and complexity of these events, the spatial distribution of TB needs to be understood, mainly in the endemic regions, with a view to supporting managers in planning and decision making in the field of health policies and practices aimed at the most vulnerable populations and areas. Therefore, the aim of this study was to analyze the sociodemographic and clinical profile of individuals who needed preventable hospitalizations and re-hospitalizations due to $T B$, the costs to the local health system and the spatial pattern of occurrence of these events in a Brazilian endemic city.

\section{Methods}

\section{Study design and setting}

Descriptive and exploratory study [16], undertaken in the city of Natal, the state capital of Rio Grande do Norte (RN), located in the Northeast region of Brazil (Figure 1). It has an estimated population of 862,044 inhabitants in an area of $167.2 \mathrm{~km}^{2}$ [17], geographically divided in 36 neighborhoods. The neighborhoods are distributed in five administrative health regions, which correspond to the Health Districts: North I, North II, South, East and West [18].

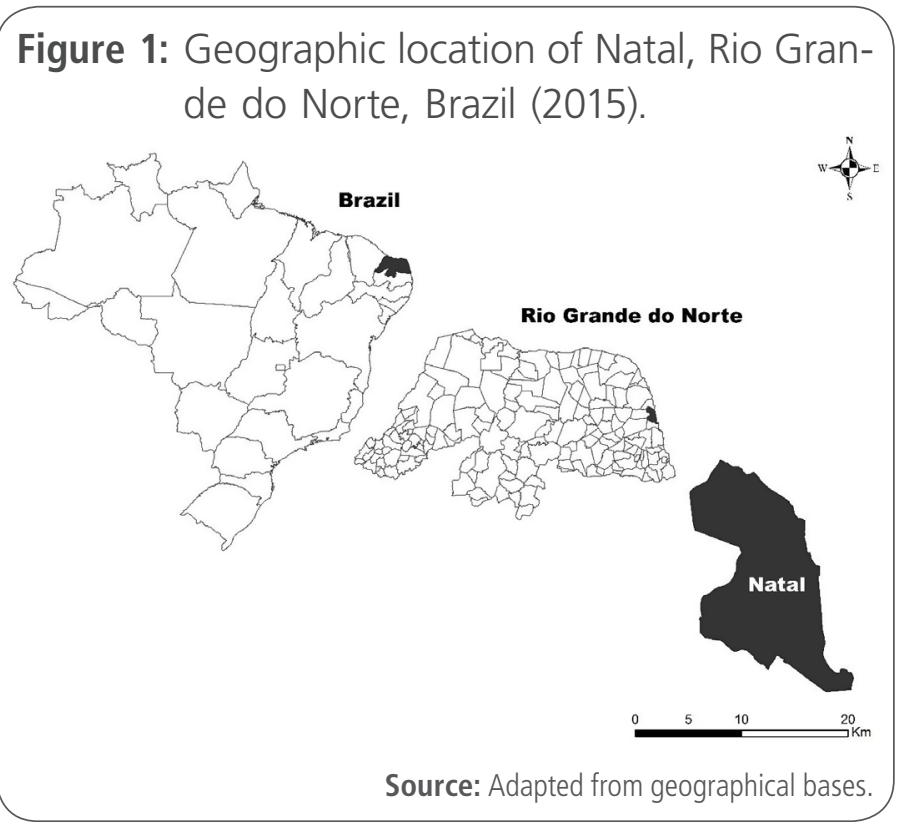

In terms of social and economic indicators, the city is classified in the High Human Development, with a Municipal Human Development Index (MHDI) equal 0.763 , thus ranking $320^{\text {th }}$ among the 5,565 Brazilian cities. Nevertheless, Natal is one of the Brazilian cities with the greatest income inequality, with a Gini index of 0.61 in 2010. Moreover, the city has a Social Exclusion Index (SEI) of about 0.6 and a Poverty Index of $40.86 \%$, according to data from the Brazilian Human Development Atlas [19].

\section{Study population, case definitions, data source and study measures}

Data were collected from the Hospital Information System of the Unified Health System (SIH/SUS), in the Outpatient and Inpatient Processing Sector of the Municipal Health Department of Natal/RN. The $\mathrm{SIH} / \mathrm{SUS}$ is a nationwide administrative database where the records of all hospitalizations funded by SUS are processed.

The Authorization of Hospitalization $(\mathrm{AlH})$ is the register all SUS managers and service providers use to document the services provided and the subsequent transmission of funding to the public and private health services affiliated with the SUS [20]. It contains information about the hospital, the patient, the hospitalization and the hospital costs. 
The research population consisted of all cases of preventable hospitalizations and re-hospitalizations due to TB registered in the SIH/SUS between 2008 and 2013. In the data selection process, the $\mathrm{AlH}$ of people living in urban Natal were considered if they were registered in the SIH/SUS under codes A15.0 till A17.9 of the International Classification of Diseases version 10 (ICD - 10). These codes include the clinical forms of TB that are acknowledged as preventable according to the official list of $\mathrm{BMH}$ [21]. The non-preventable forms of TB were not considered in this study.

In this study, preventable hospitalizations are considered to be the admissions to a hospital due to TB, including the clinical forms of TB mentioned above, which could have been reduced and/or avoided through early diagnosis, timely treatment and problem-solving management at the PHC level. Preventable re-hospitalization is defined as an episode of hospital admission due to the clinical forms of TB mentioned earlier, which happened after the discharge from the first admission. Only one re-hospitalization event was considered per case.

The preventable hospitalizations and re-hospitalizations due to TB of people living in other places were excluded, as were hospitalizations and re-hospitalizations for other clinical forms of TB that are not considered preventable, besides rehospitalizations due to administrative discharges in cases of long-term hospitalizations and/or rejected $\mathrm{AlH}$. In those cases in which more than one $\mathrm{AlH}$ was used for the same individual/hospitalization, the sociodemographic and clinical data of the first $\mathrm{AlH}$ registered were considered. The costs were obtained by adding up all AlHs registered for that hospitalization episode. For the variable "reason for departure", the information registered in the final AlH was considered.

The research variables collected in the system included location variables: street, number, neighborhood and Zip code; sociodemographic charac- teristics: age, sex and race/color; and the variables that characterized the clinical profile: clinical form, hospitalization to Intensive Care Unit (ICU), re-hospitalizations, reason for departure from hospital and the hospitalization and re-hospitalization costs. To analyze the costs, an exchange rate of US $\$ 1=R \$ 3.71$ was adopted.

\section{Statistical analysis}

Initially, the descriptive analysis of the data was conducted with the software Statistica version 12.0, including central trend measures for continuous variables and absolute and relative frequencies for categorical variables. The continuous variable age was ranked according to the literature [22] and divided as follows: 0-29 years, 30-59 years, 60 or older.

In the bivariate analysis, the crossing between the dependent variable re-hospitalizations (yes or no) and the independent variables (sociodemographic characteristics and other clinical characteristics) was considered, by applying the chi-squared test of proportions with Yates' correction or Fisher's exact test. In this phase, hospitalization records with ignored or incomplete variables were excluded from the analysis.

In addition, the Kolmogorov-Smirnov test was applied to verify the normality of the continuous variables. In case the premises for the parametric analysis were not attended to, the Mann-Whitney test $(U)$ was applied to investigate the relation between these variables and the re-hospitalization variable.

To identify the areas vulnerable to the occurrence of preventable hospitalizations and re-hospitalizations due to TB, initially, the home addresses of the cases of hospitalization and re-hospitalization were geocoded, using the software TerraView 4.2.2.

The 895 census tracts and 36 neighborhoods of the city were accepted as the unit of analysis. The cases of hospitalization and re-hospitalization were grouped according to the units of analysis adopted. 
Based on the 2010 census population of the spatial units, the gross incidence rates were calculated for hospitalizations and re-hospitalizations by dividing the number of the cases in each spatial unit (census tracts and neighborhoods) by the population of the spatial unit. Also, the rates were adjusted according to the Global Empirical Bayesian Method for both events.

The maps directly based on the gross estimates are difficult to interpret, in view of their high instability to express the risk of a certain rare event and when the population in the region of occurrence is small, like in the neighborhoods and census tracts of the city. The estimation of the corrected rates based on the coefficients observed, using the Bayesian concepts, is more interpretive and informative, as it uses not only area information, but also neighborhood data in their calculation [23].

The spatial autocorrelation of the hospitalization and re-hospitalization rates due to TB was verified using Moran's index (I), a global measure of the degree of spatial association. To analyze the spatial distribution pattern and the cluster intensity (random or dispersed cluster) according to census tracts and neighborhoods, the local Moran index (II) was used (ranging between -1 and 1) [23].

To identify the areas with the highest, lowest and intermediary hospitalization and re-hospitalization rates due to $T B$, maps were elaborated based on the results of the of the Global Bayesian coefficients, considering the census tracts and clusters of neighborhoods according to the quadrants of Moran's mirror diagram. For Q1 (+/+), neighborhoods with high hospitalization and/or re-hospitalization rates and neighbors also with a high rate; Q2 (-/-), neighborhoods with a low rate and neighbors also with a low rate; Q3 (+/-), neighborhoods with a high rate and neighbors also with a low rate; Q4 (-/+), neighborhoods with a low rate and neighbors with a high rate. In Q1 and Q2, the spatial association is positive (neighborhoods and their neighbors with similar coefficients); on the other hand, in Q3 and Q4, the spatial association is negative (neighborhoods and their neighbors with different coefficients). In addition, to detect the significance, the Local Indicators of Spatial Association (LISA), significance map was used, where the significant associations were mapped and highlighted.

In both indices, statistical significance was set at $p<0.05$ [24]. For all tests, the type I error was set at $5 \%$.

\section{Ethical aspects}

Approval for the project was obtained from the Institutional Review Board of the University of São Paulo at Ribeirão Preto College of Nursing, under Institutional Review Board Certificate (CAAE) 24922313.7.0000.5393.

\section{Results}

In total, 569 cases of preventable hospitalizations due to TB were identified, mostly were: pulmonary form ( $n=554 ; 97.4 \%)$, between 30 and 59 years old; $(n=353 ; 62.0 \%)$; male $(n=442 ; 77.7 \%)$; mulatto $(n=$ $290 ; 87.3 \%)$. In the total group of hospitalizations, $13.4 \%$ died and $17.9 \%$ were readmitted. As regards to the reason for leaving the hospital, most hospitalized patients were discharged for improved health condition $(n=431 ; 75.7 \%)$ and $24(4.2 \%)$ were discharged against medical advice. In addition, an important part died ( $n=76 ; 13.4 \%)$ (Table 1).

Among the cases of re-hospitalization $(n=102)$, a majority was between 30 and 59 years old $(n=73 ; 71.6 \%)$, male $(n=77 ; 75.5 \%)$, mulatto $(n=62$; $92.5 \%)$, pulmonary TB $(n=100 ; 98.0 \%)$, admitted to an intensive care unit ( $n=6 ; 5.9 \%)$. Concerning the reason for departure, most of the cases of rehospitalization were discharged for improved health condition ( $n=70 ; 68.6 \%), 9$ (8.8\%) were discharged against medical advise and 15 (14.7\%) died (Table 1).

Table 1 shows also the results of the bivariate analysis, relating each of the variables with the 
Table 1. Sociodemographic and clinical characteristics of preventable hospitalization and rehospitalization due to tuberculosis, Natal, Brazil (2008-2013).

\begin{tabular}{|c|c|c|c|c|c|c|c|}
\hline \multirow{3}{*}{ Variables } & \multirow{2}{*}{\multicolumn{2}{|c|}{ Total }} & \multicolumn{4}{|c|}{ Re-hospitalization } & \multirow{3}{*}{$\begin{array}{l}\text { P- } \\
\text { value }\end{array}$} \\
\hline & & & \multicolumn{2}{|c|}{ Yes } & \multicolumn{2}{|c|}{ No } & \\
\hline & $n$ & $\%$ & $\mathrm{n}$ & $\%$ & $\mathrm{n}$ & $\%$ & \\
\hline \multicolumn{8}{|l|}{ Age } \\
\hline 09 to 29 years & 140 & 24.6 & 21 & 20.6 & 119 & 25.5 & \multirow{3}{*}{0.065} \\
\hline 30 to 59 years & 353 & 62.0 & 73 & 71.6 & 280 & 60.0 & \\
\hline 60 or more & 76 & 13.4 & 08 & 7.8 & 68 & 14.6 & \\
\hline \multicolumn{8}{|l|}{ Sex } \\
\hline Male & 442 & 77.7 & 77 & 75.5 & 365 & 78.2 & \multirow{2}{*}{0.558} \\
\hline Female & 127 & 22.3 & 25 & 24.5 & 102 & 21.8 & \\
\hline \multicolumn{8}{|l|}{ Race/color ${ }^{a}$} \\
\hline Mulatto & 290 & 87.3 & 62 & 92.5 & 228 & 86.0 & \multirow{3}{*}{0.121} \\
\hline White & 31 & 9.3 & 02 & 3.0 & 29 & 10.9 & \\
\hline Black & 11 & 3.3 & 03 & 4.5 & 08 & 3.0 & \\
\hline \multicolumn{8}{|l|}{ Clinical Form } \\
\hline Pulmonary & 554 & 97.4 & 100 & 98.0 & 454 & 97.2 & \multirow{2}{*}{0.638} \\
\hline Extrapulmonary & 15 & 2.6 & 02 & 2.0 & 13 & 2.8 & \\
\hline \multicolumn{8}{|c|}{ Hospitalization to Intensive Care Unit } \\
\hline No & 556 & 97.7 & 96 & 94.1 & 460 & 98.5 & \multirow{2}{*}{$0.007^{*}$} \\
\hline Yes & 13 & 2.3 & 06 & 5.9 & 07 & 1.5 & \\
\hline \multicolumn{8}{|c|}{ Reason for Departure } \\
\hline $\begin{array}{l}\text { Discharge } \\
\text { improved }\end{array}$ & 431 & 75.7 & 70 & 68.6 & 361 & 77.3 & \multirow{8}{*}{0.059} \\
\hline $\begin{array}{l}\text { Discharge upon } \\
\text { request }\end{array}$ & 21 & 3.7 & 02 & 2.0 & 19 & 4.1 & \\
\hline $\begin{array}{l}\text { Discharge with } \\
\text { expected return } \\
\text { for monitoring }\end{array}$ & 02 & 0.4 & 00 & 0.0 & 02 & 0.4 & \\
\hline $\begin{array}{l}\text { Discharge } \\
\text { against medical } \\
\text { advice }\end{array}$ & 24 & 4.2 & 09 & 8.8 & 15 & 3.2 & \\
\hline $\begin{array}{l}\text { Discharge for } \\
\text { other reasons }\end{array}$ & 09 & 1.6 & 03 & 2.9 & 06 & 1.3 & \\
\hline $\begin{array}{l}\text { Transfer } \\
\text { to other } \\
\text { establishment }\end{array}$ & 06 & 1.1 & 03 & 2.9 & 03 & 0.6 & \\
\hline $\begin{array}{l}\text { Death with } \\
\text { declaration } \\
\text { by assistant } \\
\text { physician }\end{array}$ & 72 & 12.7 & 14 & 13.7 & 58 & 12.4 & \\
\hline $\begin{array}{l}\text { Death with } \\
\text { declaration } \\
\text { by Forensic } \\
\text { Institute }\end{array}$ & 01 & 0.2 & 00 & 0.0 & 01 & 0.2 & \\
\hline
\end{tabular}

\begin{tabular}{|c|c|c|c|c|c|c|c|}
\hline \multirow{3}{*}{ Variables } & \multirow{2}{*}{\multicolumn{2}{|c|}{ Total }} & \multicolumn{4}{|c|}{ Re-hospitalization } & \multirow{3}{*}{$\begin{array}{c}\text { P- } \\
\text { value }\end{array}$} \\
\hline & & & \multicolumn{2}{|c|}{ Yes } & \multicolumn{2}{|c|}{ No } & \\
\hline & $n$ & $\%$ & $n$ & $\%$ & $n$ & $\%$ & \\
\hline $\begin{array}{l}\text { Death with } \\
\text { declaration } \\
\text { by Division of } \\
\text { Postmortem } \\
\text { Inspection }\end{array}$ & 03 & 0.5 & 01 & 1.0 & 02 & 0.4 & 0.059 \\
\hline Total & 569 & 100 & 102 & 100 & 467 & 100 & \\
\hline
\end{tabular}

occurrence or not of re-hospitalizations. Only the hospitalization at an intensive care unit $(p=0.007)$ revealed a statistically significant association with the re-hospitalization.

As regards hospital costs, US\$ 470,370.07 was spent on hospitalization and re-hospitalization due to TB, with an annual mean cost of US\$ 78,395.01. The median cost per hospitalization was US\$ 392.70, ranging between US\$ 20.59 and US\$ $5,867.16$, and the median cost per re-hospitalization was US\$1,342.19, ranging between US\$ 20.59 and US\$ 18,670.01. In addition, the hospital costs differ $(U=8843.50 ; p<0.001)$ between the cases of hospitalization and re-hospitalization.

In the spatial analyses, 549 (96.5\%) out of 569 cases of hospitalizations considered for the study were geocoded. Among the losses, 11 (1.9\%) were street dwellers, 9 (1.6\%) had incomplete or unknown addresses. Concerning the cases of rehospitalizations, 98 (96.0\%) out of 102 cases of re-hospitalizations were geocoded. The four cases that were not geocoded had incomplete or unknown addresses.

In Figure 2, the gross incidence rates of hospitalization and re-hospitalization per neighborhood are displayed, highlighting areas with high rates, shown in black on the maps and located in neighborhoods in the East (Rocas, Praia do Meio, Cidade Alta, Mãe Luíza) and West districts (Guarapes and Quintas).

It is important to emphasize, however, that the range of the rates displayed was reduced when the correction by the Empirical Bayes method was applied, as presented in Figures $\mathbf{3}$ and $\mathbf{4}$. 
Figure 2: Gross rates of hospitalizations-A and re-hospitalizations-B due to tuberculosis per neighborhoods, Natal, Brazil (20082013).

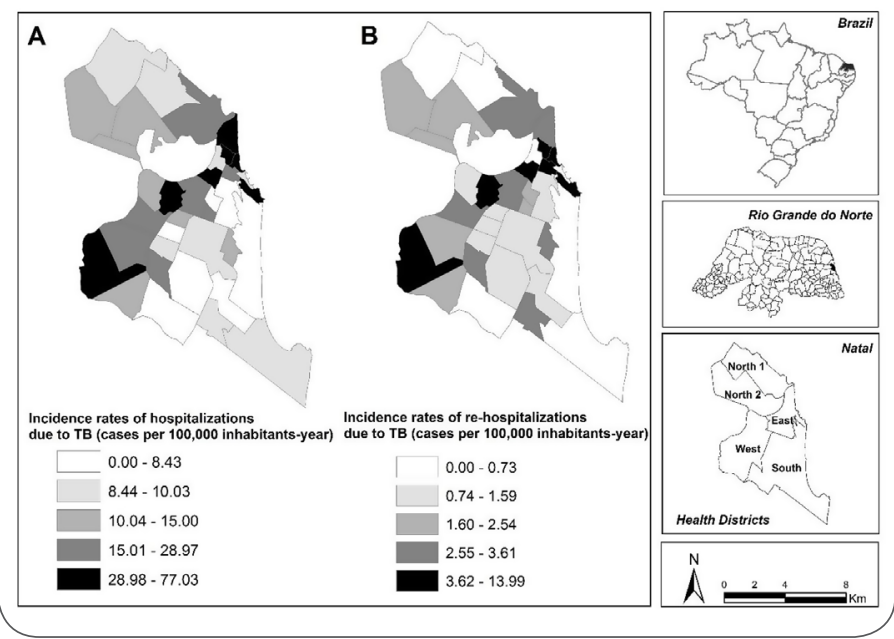

Figure 3: Bayesian rates of hospitalizations by tuberculosis per census tracts-A and neighborhoods-B, Natal, Brazil (20082013).

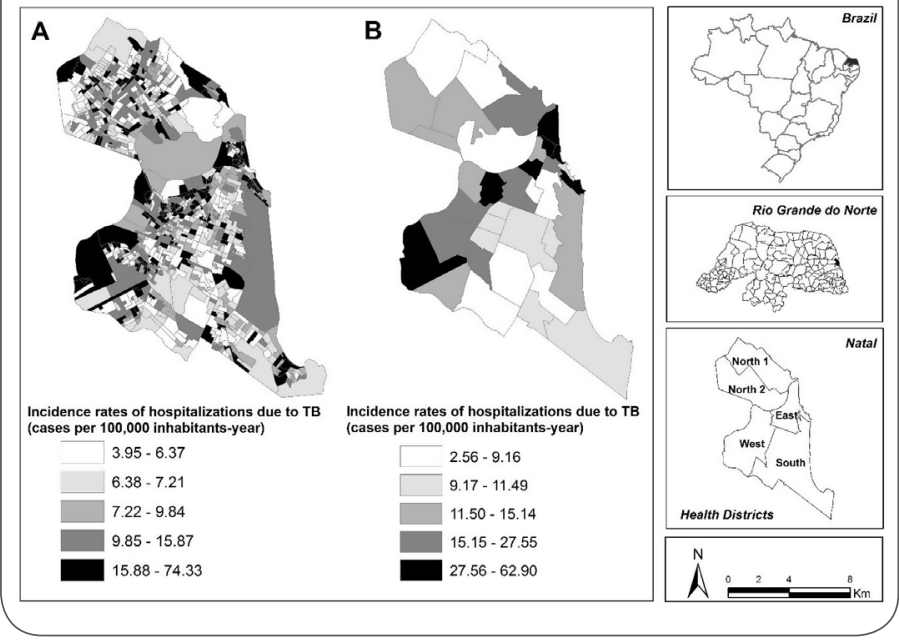

Figure 3 shows that the areas with the highest rate of preventable hospitalization due to TB are concentrated in the census tracts of the coverage areas in the West and East Health Districts. More precisely, this occurred in the neighborhoods of Guarapes, Praia do Meio, Rocas, Mãe Luiza, Quintas, Santos Reis and Cidade Alta, ranging between 27.56 and 62.90 preventable hospitalizations due to TB per 100,000 inhabitants-year.
Figure 4: Bayesian rates of re-hospitalizations by tuberculosis per census tracts-A and neighborhoods-B, Natal, Brazil (20082013).

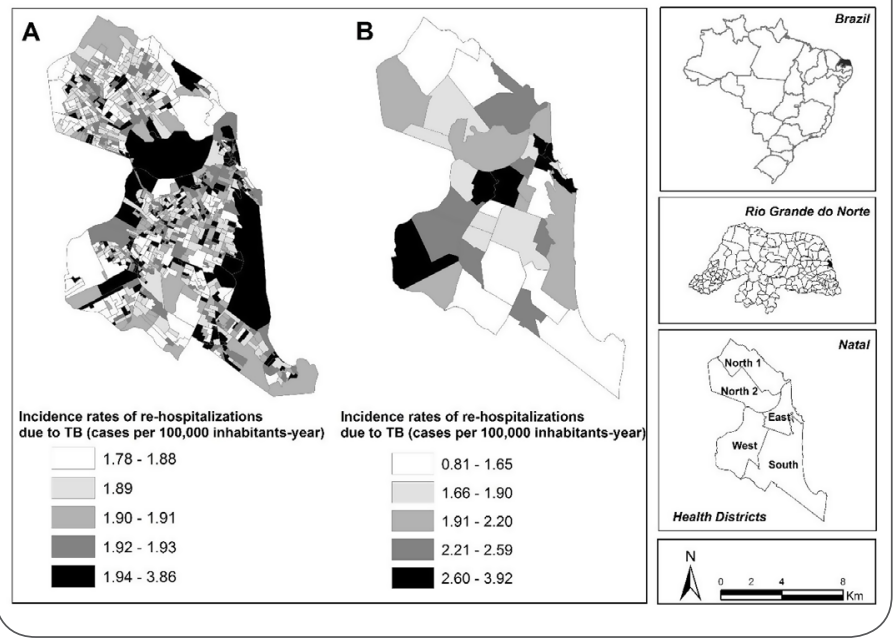

The rate of the re-hospitalizations cases (Figure 4) was also higher (ranging between 2.60 and 3.92 rehospitalizations due to TB per 100,000 inhabitantsyear) in the East and West Health Districts, especially in Praia do Meio, Rocas, Guarapes, Mãe Luíza, Quintas, Alecrim and Petrópolis neighborhoods.

In the analysis of the hospitalization rates due to $T B$, the global Moran index (I) corresponded to $0.1474(p=0.06)$ for the neighborhoods and 0.1587 $(p=0.01)$ for the census tracts. For the re-hospitalization rates due to TB, the Global Moran index (I) amounted to $0.2248(p=0.03)$ for the neighborhoods and $0.03252(p=0.04)$ for the census tracts.

Also concerning the study of the spatial correlation, in Figure $\mathbf{5}$ and $\mathbf{6}$, the behavior of the clusters was observed through the LISA, represented by the Moran Map. The areas in black (High-High) indicate the census tracts and neighborhoods with high hospitalization and re-hospitalization rates, surrounded by others in the same situation. The spatial units in light grey (Low-Low) show low hospitalization and re-hospitalization rates, surrounded by others in the same situation. The areas in dark grey (High-Low) and intermediary grey (Low-High) show the census tracts and neighborhoods with higher and lower hospitalization and re-hospitalization rates, located 
near others with lower and higher rates, respectively. The regions for which no significant associations were observed from the statistical viewpoint indicate census tracts and neighborhoods for which no spatial autocorrelation can be asserted.

The results of the LISA analysis indicated highhigh hospitalization clusters ( $n=2$ neighborhoods Santos Reis and Petrópolis, both in the East) and low-low clusters ( $n=4$ neighborhoods) in neighborhoods from the South District (Figure 5).

Figure 5: Moran Map of hospitalization rates by $T B$, census tracts-A and neighborhoodsB, Natal, Brazil (2008-2013).

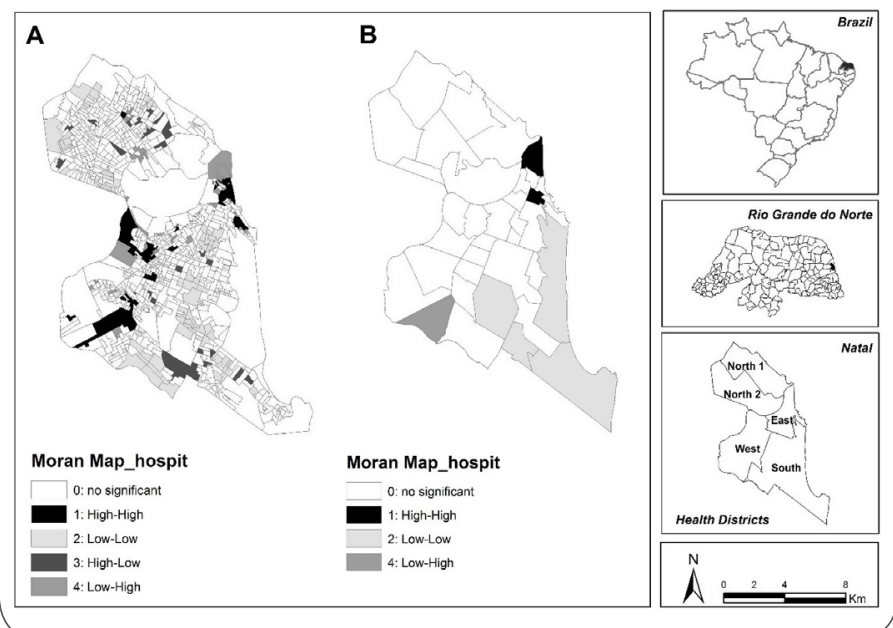

Figure 6: Moran Map of re-hospitalization rates by tuberculosis, census tracts- $A$ and neighborhoods-B, Natal, Brazil (20082013).

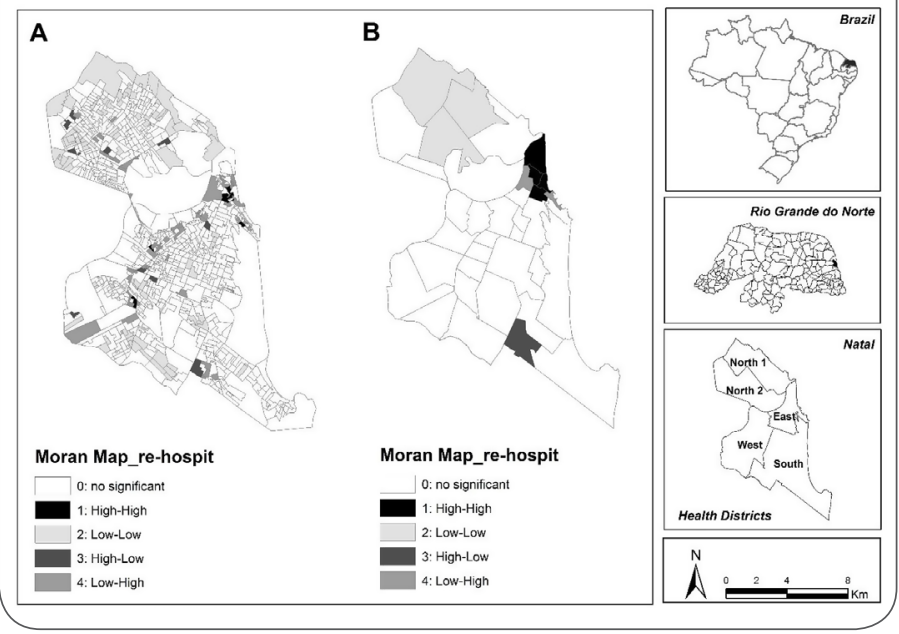

The significant re-hospitalization clusters (Figure 6) were: $n=4$ high-high neighborhoods in the areas of the East District (Santos Reis, Petrópolis, Praia do Meio and Rocas); $\mathrm{n}=1$ high-low neighborhood (Neópolis); $n=2$ low-high neighborhoods (Areia Preta and Ribeira, both in the East District); and $\mathrm{n}=3$ low-low neighborhoods in the North District (Pajuçara, Lagoa Azul and Potengi).

\section{Discussion}

The aim in this study was to analyze the sociodemographic and clinical profile of the patients who needed preventable hospitalizations and re-hospitalizations due to TB, and the costs to the local health system; and to develop a spatial analysis of these events in a Brazilian endemic city.

The analysis of the sociodemographic and clinical characteristics of the individuals who needed hospitalization and re-hospitalization due to TB showed that these research findings are in line with other studies [22, 25-30, 31,32], which mention that the largest proportion of both events is found in the male population, in the economically active age range, mulatto race/color. Also, the pulmonary clinical form of TB is predominant among the cases.

Even though the studied areas' population is predominantly female, mulatto, and in the productive age group [17], the TB hospitalization and re-hospitalization cases occur mostly among men.

In this context, studies reveal that men have a 1.6 times higher chance of being hospitalized than women [33, 34], which can be explained by the lesser frequency at which they visit health services, in combination with other factors knowingly linked to TB that are more prevalent among men, such as HIV infection; alcoholism and drugs abuse [14,35]. In addition, the hospitalization enhances the family and social damage the disease causes, as men of economically active age become unproductive during the hospitalization, which can compromise the family and professional activities and cause a high 
economic and social impact, especially in developing countries [26].

With respect to the reason for leaving the hospital, a larger proportion of cases were discharged, despite the important percentage of hospital deaths and re-hospitalizations. These outcomes are similar to those found in other studies conducted in Sub-Saharan Africa [34] and in other regions of Brazil [32]. This result gives rise to the discussion that, although TB is preventable, curable and easy to diagnose, and that free treatment is available in PHC, approximately 4.5 thousand people die each year in Brazil due to the disease [5].

The re-hospitalization expresses the PHC's difficulty to control and monitor the cases, especially in referral and counter referral communication and it acknowledges the social and economic frailties related to the disease and hospitalization. Although these patients have already been diagnosed by the health service agency and have a history of hospitalizations, the monitoring and comprehensive treatment of these cases in primary and hospital care services is deficient.

In addition, the study demonstrates that the hospitalization and re-hospitalization for TB entail high costs that the health systems cannot always bear. In Brazil, TB ranks seventh in terms of spending on hospitalizations due to infectious diseases in the Unified Health System (SUS). In 2013 alone, the country spent US\$7.188.45 on hospitalizations due to TB classified as preventable [7]. These cases might not have evolved to hospitalization if they had received appropriate care in the outpatient context [8-10]. Also, it is known that these resources are not always allocated in an efficient, universal and equitable manner among the populations and regions.

A study conducted in Canada [11], pointed out that the acknowledgement of high-risk populations and territories for re-hospitalizations could lead to substantial savings for the health system through the reduction of expenses on future hospitalizations.
In view of the above, the adoption of priority disease control and hospitalization prevention measures is necessary. Therefore, it is essential to forward these patients to the PHC service nearest to their home and to monitor their arrival at these services after the discharge [11], guaranteeing comprehensive and humanized care through Directly Observed Treatment (DOT). This technology is important because it contributes to singular patient management, offering care to adverse reactions and comorbidities, as well as social support to the patient and family with a view to avoid re-hospitalization.

Therefore, the analysis of hospitalizations and re-hospitalizations due to TB that focuses on the individual and organizational dimension of health services only, would mean rejecting determinant environmental aspects for the occurrence of this event and its influence on public health expenses, when considering that the behavior of this disease is strongly related to the living space. Therefore, it is fundamental to study these elements from a spatial distribution perspective also, integrating health data available in the Health Information Systems with environmental and social data, based on the Geographic Information System (SIG), which permits better characterization and quantification of the hospitalizations and their possible determinants.

As regards the analysis units adopted in this study, differences were found in the distribution pattern of the cases of hospitalization and rehospitalization due to TB where different analysis units may result in a variation of epidemiological indicators. In the analysis of the data per census tract, the maps produced further details of the localities in which these events occurred, revealing areas with high hospitalization and re-hospitalization rates, not visible on the neighborhood maps. The maps by neighborhood presented the distribution of the more generalized rates, important differences among the areas of the cities' different 
neighborhoods. Thus, it was possible to verify not only the neighborhoods of occurrence, but also the neighborhood that are more vulnerable to the occurrence of these events, with a view to the establishment of operational guidelines for the health services in these small areas of the city.

In the geostatistical analysis, the areas with the highest hospitalization and re-hospitalization rates due to TB were concentrated in the census tracts and neighborhoods of the East and West District. The neighborhoods Guarapes, Praia do Meio, Rocas, Mãe Luiza and Quintas stand out because they are related to high hospitalization and re-hospitalization rates due to TB. At the same time, they are known as the regions with the highest incidence and prevalence of TB [36].

The West District has the highest concentration of TB cases and the second lowest monthly income among the five Health Districts. In addition, it shows the largest number of people per home, concentrating the highest number of subnormal agglomerates and the second highest percentage of precarious settlements [18,36].

The Global Moran Index showed the existence of spatial dependence in the hospitalization and re-hospitalization rates due to TB among neighboring census tracts and/or neighborhoods. The Local Moran Index indicated the presence of hospitalization and re-hospitalization clusters. The neighborhoods with high rates and neighbors with high rates were located in the East Health District, particularly in the Santos Reis and Petrópolis neighborhoods, which presented clusters of hospitalizations and re-hospitalizations due to TB. It is important to mention that the Family Health Strategy (FHS) coverage in the East Health District corresponds to only $37 \%$ of the population, while the neighborhood Santos Reis does not have any health service [37].

The East District, despite being the least populous, stands out because of the high population density and the second highest concentration of TB cases in the city $[18,36,38]$, which can favor the transmission of the disease. In addition, the social inequality became evident in areas with high and low economic and social conditions as they shareed the same territory. Therefore, the East district demands more effective actions and services in all sectors, in view of the set of associated factors that can increase the risk of transmission, illness, hospitalization and re-hospitalizations due to TB.

However, this district show the highest percentages of population without FHS coverage and low availability of primary health care services [37]. This can provoke reduced health service access, maintenance of the disease-focused care perspective and less emphasis on promotion and prevention activities [39]. In that context, studies [40] suggest that the expansion of Primary Care is closely related with the reduction of hospitalizations and is characterized as a priority strategy to reduce costs and enhance the health systems [41, 42].

Another important issue of the study is related to the concentration of PHC in areas with social problems, which might be associated to the results of the study [43]. Therefore, an important barrier to $\mathrm{PHC}$ with populations in extreme vulnerability is the insufficient service tools available to confront the social determinants, such as inappropriate housing, food, employment, stigma, alcohol and drug use, and violence, among other problems [44].

According to a survey conducted by the city's Primary Health Care Department [37], primary health care services are concentrated in socially more benefitted areas, like in the South District, to the detriment of large care voids in areas of urban expansion and lower purchasing power of the population, such as those located in the Districts North and West.

The existence of spatial autocorrelation in the hospitalization and re-hospitalization rates supports the idea that neighboring areas tend to present mutually more similar rates which, differently from what happens between distant regions, these 
tend to share the same socioeconomic, demographic and health service access characteristics which favor clustering [44]. This strengthens the findings presented earlier concerning the frailty of PHC services and social vulnerability. The authors raise the hypothesis that areas with bad PHC services and social problems are at an increased risk of hospitalizations and re-hospitalization, which should be confirmed in future research.

In general, geographical clusters of hospitalizations and re-hospitalizations were identified, indicating potential risk areas for the occurrence of these events. However, is needed explore this results, as the areas with low rates of hospitalizations do not necessarily mean better access, considering that these can derive from underreporting or hospitalization in private services not affiliated with the SUS. Also, is needed to analyze the effects of family care and social support after the hospital discharge, which may be associated with the re-hospitalization, as well as the comorbidities and other factors admittedly associated with TB, such as alcoholism and drugs abuse. This information was not analyzed as it is not included in the AlH documents and not available in the administrative data of the SIH/SUS, due to the essentially administrative and financial nature of this system. Thus, further research is need incorporating these variables.

With regards to the research limitations, the use of secondary data could have caused some bias in the study due to the non-control of the research variables in the records. In addition, the funding source of the hospitalizations considered in the study was limited to the estimated hospital charges paid by the SUS. Hospitalization costs paid by private services not affiliated with the SUS and by health insurance companies were not included. Nevertheless, the hospitalizations due to TB in the SUS represent the large majority of internments in this group.

Nevertheless, despite the limitations, the national range of the AlH and its availability of demographic, geographic and diagnostic information for each hospitalization enhance the possibility of producing public health knowledge. It also can contribute to the recognition of the vulnerable areas whom can support managers and health professionals' decision-making and should contribute to the control of TB through improvements in health service access, and enhance the equitable distribution and efficient use of health resources. Such advances would help reduce the physical, psychological and social complications for the patient, and the preventable hospitalizations and re-hospitalizations due to this disease, thereby ameliorating their financial impact on the health system.

Lastly, the results and conclusions of the study are applicable to local management. They may also be useful to other Brazilian regional and international health systems with limited resources or similar socio-economic and health development conditions. Efficient and cost-effective application of health resources is needed in cases of avoidable hospitalizations and re-hospitalizations, especially in view of the current Brazilian and worldwide economic crises, and the recent WHO alert about TB funding and the scarce resources for disease control [45].

\section{Acknowledgments}

Acknowledgements to the Outpatient and Inpatient Processing Sector of the Municipal Health Department of Natal/RN for authorizing the development of the research and for granting the data.

\section{Funding}

The São Paulo Research Foundation (FAPESP) Process 2013/17057-5 and Process 2013/03756-9, National Council of Technological and Scientific Development (CNPQ) Process 473963/2013-2.

\section{Competing and Conflicting interest}

The authors declare that they have no competing interest. 


\section{Abbreviations}

AlH: Authorization for Hospitalization; BMH: Brazilian Ministry of Health; CAAE: Institutional Review Board Approval; DOT: Directly Observed Therapy; FHS: Family Health Strategy; HIV: Human Immunodeficiency Virus; ICD-10: International Classification of Diseases version 10; ICU: Intensive Care Unit; LISA: Local Indicators of Spatial Association; MHDI: Municipal Human Development Index; PHC: Primary Health Care; RN: Rio Grande do Norte; SIG: Geographic Information System; SIH/SUS: Hospital Information System of the Unified Health System; SUS: Unified Health System; TB: Tuberculosis; WHO: World Health Organization;

\section{References}

1. World Health Organization (WHO). Stop TB Partnership: The Global Plan To Stop TB. Geneva, 2011. 102 p. [cited 2016 June 25] Available from: http://apps.who.int/iris/ bitstream/10665/44437/1/9789241500340 eng.pdf

2. World Health Organization (WHO). Global tuberculosis report 2014. Geneva, 2014. 171 p. [cited 2016 Apr 16] Available from: http://apps.who.int/iris/ itstream/10665/137094/1/9789241564809 eng.pdf?ua=1. http:// apps.who.int/iris/bitstream/10665/137094/1/9789241564809 eng.pdf?ua=1

3. Mendes EV. As redes de atenção à saúde. 2nd ed. Brasília-DF: Organização Pan-Americana da Saúde; 2011.

4. Arakawa T, Arcêncio RA, Scatolin BE, Scatena LM, RuffinoNetto A, Villa TCS. Acessibilidade ao tratamento de tuberculose: avaliação de desempenho de serviços de saúde. Rev. Latino Am. De Enfermagem. 2011; 19(4):1-9.

5. Brasil. Ministério da Saúde (MS), Secretaria de Vigilância em Saúde. Boletim Epidemiológico. Brasília, 2015. 19 p. [cited 2015 May 02] Available from: http://portalsaude.saude.gov.br/ images/pdf/2015/marco/27/2015-007---BE-Tuberculose---parasubstitui----o-no-site.pdf

6. Hijjar MA, Procópio MJ, Freitas LM, Guedes R, Bethem EP. Epidemiologia da tuberculose: importância no mundo, no Brasil e no Rio de Janeiro. Pulmão RJ. 2005; 14(4):310-314.

7. Brasil. Departamento de Informática do Sistema Único de Saúde do Brasil (DATASUS). Arquivo de dados referentes a Autorizações de Internações Hospitalares no Brasil. Brasília, 2013. [cited 2015 Apr. 30] Available from: http://www2.datasus.gov.br/DATASUS/ index.php?area $=0901 \&$ item $=1$ \&acao $=25$
8. Alfradique ME, Bonolo PF, Dourado I, Lima-Costa MF, Macinko J, Mendonça CS, et al. Internações por condições sensíveis à atenção primária: a construção da lista brasileira como ferramenta para medir o desempenho do sistema de saúde (Projeto ICSAP - Brasil). Cad Saúde Pública. 2009; 25(6):13371349.

9. Fernandes $V B L$, Caldeira $A P$, Faria $A A$, Rodrigues Neto JF. Internações sensíveis na atenção primária como indicador de avaliação da Estratégia Saúde da Família. Rev. Saúde Pública. 2009; 43(6):928-936.

10. Centers for Disease Control and Prevention. Potentially Preventable Hospitalizations, United States, 2001-2009. MMWR. 2013; 62 Suppl 3:139-143.

11. Cui $Y$, Torabi M, Forget EL, Metge $C$, Ye $X$, Moffatt $M$, et al. Geographical variation analysis of all-cause hospital readmission cases in Winnipeg, Canada. BMC Health Services Research. 2015; 15:129-135. doi:10.1186/s12913-015-0807-2

12. Mendes EV. O cuidado das condições crônicas na atenção primária à saúde: o imperativo da consolidação da estratégia da saúde da família. Brasília-DF: Organização Pan-Americana da Saúde, 2012.

13. Centers for Disease Control and Prevention. CDC Health disparities and inequalities report, United States, 2011. MMWR. 2011; 60 Suppl l:1-109.

14. Scatena LM, Villa TCS, Netto AR, Kritski AL, Figueiredo TMRM, Vendramini SHF, et al. Dificuldades de acesso a serviços de saúde para diagnóstico de tuberculose em municípios do Brasil. Rev. Saúde Pública. 2009; 43(3):389-97.

15. Curtis S. Health and Inequality: Geographical Perspectives. London: Sage Publications, 2004.

16. Gordis, L. Epidemiology. Philadelphia: Elsevier/Saunders, 2014.

17. Brasil. Instituto Brasileiro de Geografia e Estatística. Cidades: Censo demográfico 2010. Brasília, 2010. [cited 2015 May 02] Available from: http://cod.ibge.gov.br/232RL

18 Hora CEP, Medeiros FAC (Orgs). ANUÁRIO NATAL 2014. Natal: SEMURB, 2014. 404 p. [cited 2015 May 02] Available from: http://www.natal.rn.gov.br/semurb/paginas/ctd-102.html

19. Programa das Nações Unidas para o Desenvolvimento (PNUD). Atlas do Desenvolvimento Humano no Brasil. Brasília, 2013. [cited 2015 May 02] Available from: http://www.atlasbrasil.org. br/2013/

20. Bittencourt SA, Camacho LA, Leal MC. O Sistema de Informação Hospitalar e sua aplicação na saúde coletiva. Cad Saúde Pública. 2006; 22:19-30.

21. Brasil. Ministério da Saúde (MS). Portaria n. 221 de 17 de abril de 2008. Define a Lista Brasileira de Internações por Condições Sensíveis à Atenção Primária. Diário Oficial da União, Poder Executivo, Brasília-DF, 18 abr. 2008.

22. Cecilio HP; Molena-Fernandes CA; Mathias TAF; Marcon SS. Perfil das internações e óbitos hospitalares por tuberculose. Acta Paul Enferm. 2013; 26(3):250-255.

23. Medronho RA, Werneck GL. Análise de dados espaciais em saúde. In: Medronho RA, Bloch KV, Luiz RR, Werneck GL. Epidemiologia. São Paulo: Atheneu; 2009. p. 493-514. 
24. Duarte-Cunha M, Souza-Santos R, Matos HJ, Oliveira MLW. Aspectos epidemiológicos da hanseníase: uma abordagem espacial. Cad. Saúde Pública. 2012 June; 28(6):1143-55.

25. Oliveira U, Brescovit AD, Santos AJ. Delimiting Areas of Endemism through Kernel Interpolation. Plos one. 2015; 10(1):118. doi:10.1371/journal.pone.0116673.

26. Oliveira NF, Gonçalves MJ. Social and environmental factors associated with the hospitalization of tuberculosis patients. Rev Lat Am Enfermagem. 2013; 21(2):507-514.

27. Maciel SSSV, Maciel WV, Oliveira DAL, Oliveira TF, Silva ETC, Sobral LV. Internação hospitalar por tuberculose respiratória nas gerências regionais de saúde de Pernambuco. Revista da AMRIGS. 2011; 55(3):229-233.

28. Perrechi MCT, Ribeiro AS. Desfechos de tratamento de tuberculose em pacientes hospitalizados e não hospitalizados no município de São Paulo. J Bras Pneumol. 2011; 37(6):783790.

29. Silva DR, Silva LP, Dalcin PTR. Tuberculosis in hospitalized patients: clinical characteristics of patients receiving treatment within the first $24 \mathrm{~h}$ after admission. J Bras Pneumol. 2014; 40 (3): 279-285. J Bras Pneumol. 2014 May-Jun; 40(3):279-285. doi:10.1590/S1806-37132014000300011.

30. Touray K, Adetifa IM, Jallow A, Rigby J, Jeffries D, Cheung YB, et al. Spatial analysis of tuberculosis in an Urban West African setting: is there evidence of clustering? Tropical Medicine and International Health. 2010; 15(6):664-672. doi: 10.1111/j.13653156.2010.02533.x.

31. Perrechi MCT, Ribeiro AS. Tratamento de tuberculose: integração entre assistência hospitalar e rede básica na cidade de São Paulo. J Bras Pneumol. 2009; 35(6):1100-1106.

32. Oliveira HMMG, Brito RC, Kritski AF, Ruffino-Netto A. Perfil epidemiológico de pacientes portadores de TB internados em um hospital de referência na cidade do Rio de Janeiro. J. Bras. Pneumol. 2009; 35(8):780-787.

33. Hargreaves JR, Boccia D, Evans CA, Adato M, Petticrew M, Porter $\mathrm{JDH}$. The Social Determinants of Tuberculosis: From Evidence to Action. Am J Public Health. 2011; 101(4):654-62.

34. Oliveira GP, Torrens AW, Bartholomay P, Barreira D. Tuberculosis in Brazil: last ten years analysis - 2001-2010. Braz J Infect Dis. 2013; 17(2):218-233.

35. Thomas JA, Laraque F, Munsiff S, Piatek A, Harris TG. Hospitalizations for tuberculosis in New York City: how many could be avoided? Int j tuberc lung dis. 2010; 14(12):1603-1612.

36. Natal. Secretaria Municipal de Saúde (SMS). Plano Municipal de Saúde de Natal-RN - Gestão 2010-2013 - Execução 2011-2013. Natal: SMS, 2010. 187 p. [cited 2015 Apr 30] Available from: https://www.natal.rn.gov.br/sms/paginas/File/SMS-PMS20112013v5.pdf>

37. Natal. Secretaria Municipal de Saúde, Departamento de Atenção Básica: Carteira de Serviços da Atenção Básica de Natal. 2014.

38. Cavalcante EFO, Silva DMGV. Perfil de pessoas acometidas por Tuberculose. Rev. Rene. 2013; 14(4):720-729.

39. Ceccon RF, Meneghel SN, Viecili PRN. Internações por condições sensíveis à atenção primária e ampliação da Saúde da Família no Brasil: um estudo ecológico. Rev. bras. epidemiol. 2014; 17(4):968-97.
40. Ceccon RF, Borges DO, Paes LG, Klafke JZ, Viecili PRN. Mortalidade por doenças circulatórias e evolução da saúde da família no Brasil: um estudo ecológico. Ciênc Saúde Coletiva. 2013; 18(5):1411-1416

41. Dourado I, Oliveira VB, Aquino R, Bonolo P, LimaCosta MF, Medina $M G$, et al. Trends in primary health care-sensitive conditions in Brazil: the role of the Family Health Program (Project ICSAP-Brazil). Med Care. 2011; 49(6):577-84.

42. Eggli $Y$, Desquins $B$, Seker $E$, Halfon P. Comparing potentially avoidable hospitalization rates related to ambulatory care sensitive conditions in Switzerland: the need to refine the definition of health conditions and to adjust for population health status. BMC Health Serv Res. 2014; 14:25.

43. Harling G, Castro MC. A spatial analysis of social and economic determinants of tuberculosis in Brazil. Health Place. 2014, 25:5667.

44. Antunes FP, Costa MCN, Paim JS, Vieira-da-Silva LM, Cruz AA, Natividade $M$, et al. Desigualdades sociais na distribuição espacial das hospitalizações por doenças respiratórias. Cad. Saúde Pública. 2013; 29(7):1346-1356.

45. World Health Organization (WHO). Global tuberculosis report 2016. Geneva, 2016. 171 p. [cited 2016 Nov 16] Available from: http://apps.who.int/iris/bitstre am/10665/250441/1/9789241565394-eng.pdf?ua=1

\section{Publish in International Archives of Medicine}

International Archives of Medicine is an open access journal publishing articles encompassing all aspects of medical science and clinical practice. IAM is considered a megajournal with independent sections on all areas of medicine. IAM is a really international journal with authors and board members from all around the world. The journal is widely indexed and classified Q2 in category Medicine. 